\title{
Persistence of tropical ataxic neuropathy in a Nigerian community
}

\author{
O S A Oluwole, A O Onabolu, Hans Link, Hans Rosling
}

Neurology Unit, Department of Medicine, University of Ibadan, Nigeria O S A Oluwole

International Institute for Tropical

Agriculture, Ibadan, Nigeria

O S A Oluwole

A O Onabolu

Division of

International Health, IHCAR, Department of Public Health

Sciences, Karolinska

Institute, SE-171 76

Stockholm, Sweden

O S A Oluwole

A O Onabolu

H Rosling

Division of Neurology,

Huddinge Hospital,

Karolinska Institute,

Sweden

H Link

Correspondence to:

Dr O S A Oluwole

osaoluwole@hotmail.com

Received 15 July 1999 and in revised form

29 December 1999

Accepted 9 February 2000

\begin{abstract}
Objectives-The term tropical ataxic neuropathy (TAN) is currently used to describe several neurological syndromes attributed to toxiconutritional causes. However, TAN was initially proposed to describe a specific neurological syndrome seen predominantly among the Ijebu speaking Yorubas in south western Nigeria. In this study, the prevalence of TAN was determined in Ososa, a semiurban community in south western Nigeria described as endemic for TAN in 1969, and its neurological features were compared with Strachan's syndrome, prisoners of war neuropathy, the epidemic neuropathy in Cuba, and konzo.
\end{abstract}

Methods-A census of Ososa was followed by door to door screening of all subjects aged 10 years and above with a newly designed screening instrument. Subjects who screened positive had a neurological examination, and the diagnosis of TAN was made if any two or more of bilateral optic atrophy, bilateral neurosensory deafness, sensory gait ataxia, or distal symmetric sensory polyneuropathy were present.

Results-A total of 4583 inhabitants were registered in the census. Of these, 3428 subjects aged 10 years and above were screened. The diagnosis of TAN was made in 206 of 323 subjects who screened positive for TAN. The prevalence of TAN was $6.0 \%, 3.9 \%$ in males and $7.7 \%$ in females. The highest age specific prevalence was $24 \%$ in the $60-69$ years age group in women.

Conclusion-The occurrence of TAN in Ososa continues at a higher prevalence than was reported 30 years ago. Its neurological features and natural history do not resemble those described for Strachan syndrome, epidemic neuropathy in Cuba, or konzo. The increasing consumption of cassava foods linked to its causation makes TAN of public health importance in Nigeria, the most populous African country. ( $\mathcal{A}$ Neurol Neurosurg Psychiatry 2000;69:96-101)

Keywords: tropical myeloneuropathy; nutritional polyneuropathy; ataxia

Several neurological syndromes described from different tropical regions in the past century $^{1-4}$ have been classified as tropical myeloneuropathies and further grouped into tropical ataxic neuropathy (TAN) and tropical spastic paraparesis. ${ }^{5}$ The syndromes grouped as TAN differ widely in clinical presentation, natural history, and response to treatment. Two of the neurological syndromes grouped as tropical ataxic neuropathy were described in Nigeria in the past 60 years.

In 1930, a syndrome that affected predominantly adolescent school pupils in several boarding schools was reported from some communities in eastern and western parts of Nigeria..$^{6-8}$ The main clinical features were sore tongue, angular stomatitis, and skin desquamations followed by optic atrophy in a large proportion of cases. Recovery of the lesions occurred during holidays, but many affected pupils had a recurrence on returning to school. ${ }^{9}$ The school diet, dominated by cassava food products, was implicated as causal and almost $100 \%$ of the patients responded to improvement of diet and supplements with autoclaved dried yeast. ${ }^{9}$ The second syndrome, unlike the syndrome of the 1930s, affected middle aged and elderly people predominantly and its geographical distribution was limited to some communities in south western Nigeria. ${ }^{40}$ It was variously named endemic neuropathy ${ }^{4}$ degenerative neuropathy, ${ }^{11}$ tropical nutrition neuropathy, ${ }^{12}$ and tropical ataxic neuropathy. ${ }^{13}$ Different combinations of sensory polyneuropathy, bilateral optic atrophy, bilateral neurosensory deafness, and sensory gait ataxia were found. ${ }^{4}{ }^{13}$ Its causation was attributed to dietary cyanide from the monotonous consumption of foods ${ }^{13-15}$ processed from the starchy roots of cassava (Manihot esculenta esculenta). ${ }^{16}$ In contradistinction to the first syndrome, cases did not respond to improvement in diet or vitamin supplementation. ${ }^{17} 18$

In the 1980s, the occurrence of TAN was reported to have subsided because cases were no longer registered in the teaching hospitals. It was speculated that improvement in diet, which followed the oil boom economic recovery period of the 1970s in Nigeria, caused the disappearance of the syndrome. ${ }^{19}$ However, a recent food survey in Ososa (fig 1), a semiurban community of Ijebu speaking Yorubas in south western Nigeria previously surveyed for TAN in $1969,{ }^{11}$ showed that about $80 \%$ of the population consumed foods processed from the starchy roots of cassava thrice daily. ${ }^{20}$ The possibility that TAN may still be occurring in this community motivated this study.

The aim of this study was to determine the prevalence of TAN in Ososa, and to compare its neurological features with those described for Strachan's syndrome, ${ }^{1}$ prisoner of war neuropathy, ${ }^{2}$ epidemic neuropathy of $\mathrm{Cuba},{ }^{21}$ 


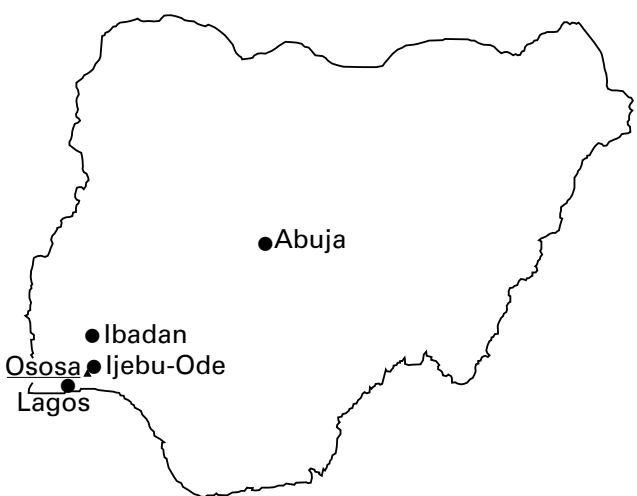

Figure 1 Map of Nigeria showing Ososa in relation to some major towns.

and konzo, which is also attributed to exposure to dietary cyanide. ${ }^{22}$

\section{Subjects and methods}

STUDY SITE

Ososa is a semiurban community in the Odogbolu local government area of Ogun State, Nigeria, where TAN was endemic in the 1960 s. $^{11}$ This community, divided into seven administrative quarters from historical antecedents, has an indigenous population of Ijebus, an ethnic group of the Yoruba tribe. All houses in the town are cement faced but vary widely in size and quality. Small scale cassava farming is the source of livelihood of most of the population. Social amenities such as electricity, water, good road networks, and motor transport are within access of all inhabitants.

CENSUS

All houses in Ososa were numbered, and every member of each household had their names, ages, and sex recorded. Subjects without birth records had their ages estimated to the nearest 5 years through comparison with peers whose ages were known and belong to the same "age group society" peculiar to the local culture.

\section{SCREENING}

A screening questionnaire with items to assess visual, auditory, motor, gait, and somatosensory symptoms consistent with the clinical neurology of TAN as previously described in studies from Nigeria $^{23}$ was developed. The questionnaire was prepared in the English language and translated to the local language, Yoruba, by two independent translators, who subsequently agreed on consensus translation. The consensus translation was translated back into English to check for accuracy before final translation to the Yoruba language. The questionnaire was tested and piloted on 10 subjects and then revised. The tandem walk examination was added as a clinical test to improve the sensitivity of the questionnaire. The tandem walk test was standardised by making the subjects walk heel to toe in a straight line, looking straight ahead with hands by the side over a distance of 3 metres. The first author assessed the performance of the test. A door to door screening was done with the com- bination of the questionnaire and the tandem walk test. Only subjects 10 years of age and above were screened as previous reports showed TAN to be rare below the age of 10 years. ${ }^{10}{ }^{15}$ Subjects who screened positive from either the questionnaire or the tandem walk test were invited for neurological examination at the local health centre in Ososa.

\section{HISTORY AND EXAMINATION}

In two of the seven quarters in Ososa, Idomowo, and Odolakoye, all subjects who screened positive had a detailed history taken, and a clinical and neurological examination, and those diagnosed with TAN had their urine tested for sugar and protein. These two quarters were purposely sampled to represent the known socioeconomic variations among all quarters. In depth interviews to determine the history of illness and exposure to industrial chemicals, drugs, and pesticides were carried out. Detailed neurological examination with standard methods assessed higher cerebral functions, cranial nerves, motor system, coordination, gait, and somatosensory modalities of pain, touch, joint position, and vibration..$^{24}{ }^{25} \mathrm{In}$ the remaining five quarters subjects who screened positive had an abbreviated neurological examination more focused on specific modalities required for the diagnosis of TAN.

\section{DIAGNOSIS}

The diagnosis of TAN was made when any two or more of bilateral optical atrophy, bilateral neurosensory deafness, distal symmetric sensory polyneuropathy, or sensory gait ataxia were present as defined in previous studies. ${ }^{101315}$ The diagnostic criteria were defined as follows: optic atrophy required distinct pallor of at least half of the disc; neurosensory deafness required impairment of Rinne's test; sensory polyneuropathy required impairment of pin prick at a level above the malleoli and wrist on both extensor and flexor surfaces; and gait ataxia required impairment of tandem walk.

\section{CONSENT}

Consent for this study was obtained from the local government health authority, the mon$\operatorname{arch}(\mathrm{Oba})$ of Ososa, chiefs of the quarters, and heads of families.

\section{Results}

\section{EPIDEMIOLOGY}

A total of 4583 inhabitants was registered in the census. Of these, 3428 subjects aged 10 years and above were screened and 323 were positive for TAN. Sixty six patients screened positive on all the five items of the screening instrument, 94 on all items of the questionnaire only, and 15 on tandem walk test only. The remaining 148 were positive on various combinations of the questionnaire items and the tandem walk test. In the two selected quarters all the 93 patients who screened positive were examined but in the remaining five quarters 37 of the patients who screened positive defaulted. The mean age of the defaulters was 50 years 
Table 1 Number of subjects screened and examined per quarter

\begin{tabular}{|c|c|c|c|c|c|c|}
\hline \multirow[b]{2}{*}{ Quarter } & \multicolumn{2}{|c|}{ Screening } & \multicolumn{4}{|c|}{ Diagnosis at examination } \\
\hline & Total & Positive & TANt & $S P N^{*}$ & Others & Total \\
\hline Idomowo & 440 & 46 & 33 & 12 & 1 & 46 \\
\hline Ijoku & 441 & 46 & 22 & 2 & 6 & 30 \\
\hline Odo-Alere & 419 & 47 & 33 & 6 & 6 & 45 \\
\hline Odo-Owa & 558 & 37 & 24 & 4 & 5 & 33 \\
\hline Odolakoye & 692 & 47 & 33 & 8 & 6 & 47 \\
\hline Oke-Ala & 494 & 69 & 47 & 1 & 12 & 60 \\
\hline Oke-Esin & 384 & 31 & 14 & 8 & 3 & 25 \\
\hline Total & 3428 & 323 & 206 & 41 & 39 & 286 \\
\hline
\end{tabular}

Table 2 Age and sex distribution of subjects screened and age specific prevalence

\begin{tabular}{|c|c|c|c|c|c|c|}
\hline \multirow{2}{*}{$\begin{array}{l}\text { Age } \\
\text { group (y) }\end{array}$} & \multicolumn{2}{|c|}{ Screened } & \multicolumn{2}{|c|}{ TAN patients } & \multicolumn{2}{|c|}{ Prevalence (\%) } \\
\hline & Male & Female & Male & Female & Male & Female \\
\hline $10-19$ & 566 & 508 & 3 & 3 & 0.5 & 0.6 \\
\hline $20-29$ & 222 & 356 & 1 & 4 & 0.5 & 1.1 \\
\hline $30-39$ & 186 & 272 & 1 & 10 & 0.5 & 3.7 \\
\hline $40-49$ & 161 & 199 & 5 & 19 & 3.1 & 10.0 \\
\hline 50-59 & 134 & 193 & 5 & 36 & 3.7 & 18.7 \\
\hline $60-69$ & 153 & 168 & 24 & 41 & 15.7 & 24.4 \\
\hline $70-79$ & 81 & 108 & 14 & 24 & 17.3 & 22.2 \\
\hline$>80$ & 44 & 77 & 8 & 8 & 18.0 & 10.4 \\
\hline Total & 1547 & 1881 & 61 & 145 & 3.9 & 7.7 \\
\hline
\end{tabular}

(SD 20 years) compared with the mean age of 58 years (SD 17 years) for the 286 subjects (204 females and 82 males) examined.

The number of subjects that were screened and examined in each quarter is shown in table 1. The diagnosis of TAN was made in 206 $(72 \%)$ of the 286 subjects examined. Sixty one were men and 145 were women with a mean age of 62 (SD 17), and 57 (SD 15) years respectively. The median age for all patients with TAN was 61 years (range 10 to 95 years). Sensory polyneuropathy without other signs was diagnosed in 41 patients. The other diagnoses were optic atrophy without other signs in five patients, cerebellar disease in four patients, sensory ataxia without other signs in three patients, and Parkinson's disease in one patient. Thirteen subjects were normal, $11 \mathrm{had}$ osteoarthritis, one had a leg ulcer, and in one subject it was not possible to make a diagnosis due to incomplete data.

The age specific prevalence for TAN is shown in table 2 . The prevalence of TAN was $6.0 \%$ above 10 years of age. Age specific prevalence was highest in the 60-69 year age group in women. All cases belonged to the Ijebu ethnic group and all but one were living in Ososa at the time of onset of disease. The prevalence of distal symmetric sensory polyneuropathy was $1.2 \%$ above the age of 10 years.

Table 3 Combinations of signs in 206 TAN patients

\begin{tabular}{lc}
\hline Signs & $n(\%)$ \\
\hline Two signs: & \\
Sensory polyneuropathy+gait ataxia & $90(43.7)$ \\
Sensory polyneuropathy+optic atrophy & $28(13.6)$ \\
Sensory polyneuropathy+neurosensory deafness & $2(1.0)$ \\
Optic atrophy+neurosensory deafness & $4(2.0)$ \\
Three signs: & $44(21.0)$ \\
Sensory polyneuropathy+gait ataxia+optic atrophy & $16(7.7)$ \\
Sensory polyneuropathy+gait ataxia+neurosensory deafness & $4(2.0)$ \\
Sensory polyneuropathy+optic atrophy+neurosensory deafness & $18(8.7)$ \\
All the four signs & \\
\hline
\end{tabular}
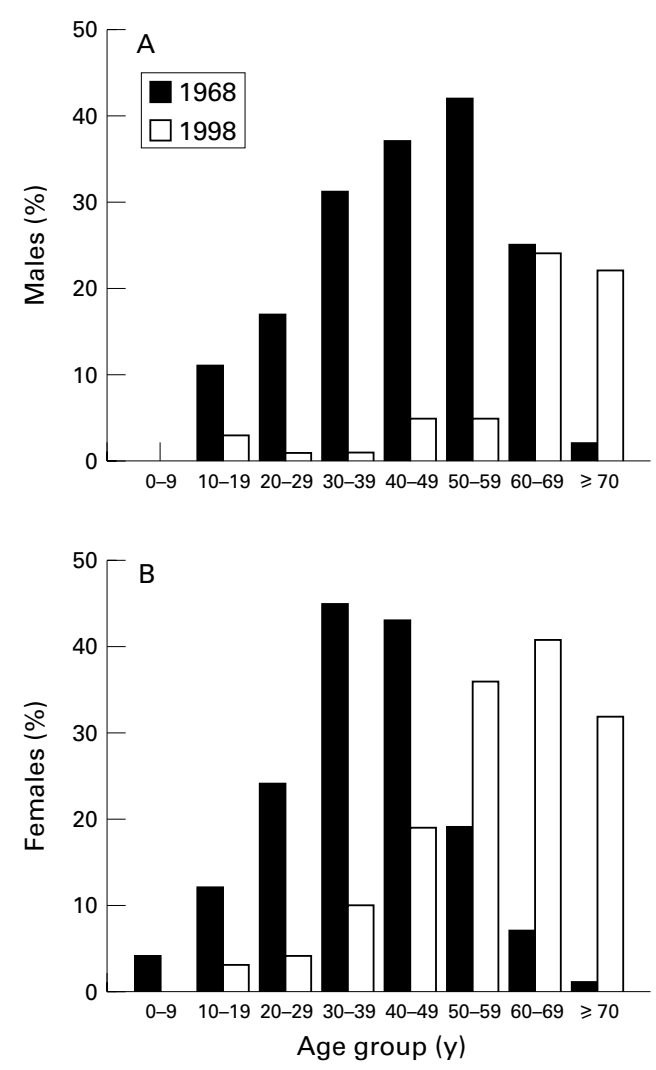

Figure 2 Age distribution of men (A) and women (B) in the 1968 case series (filled column) and present study (open column).

NEUROLOGICAL AND CLINICAL FINDINGS IN ALL 206 PATIENTS WITH TAN

Of the 206 patients, glove and stocking sensory impairment of pain and touch sensibilities were found in 202 (98\%), sensory gait ataxia in 172 (84\%), optic atrophy in 98 (48\%), and neurosensory deafness in 40 (19\%). Table 3 shows the combinations of signs. Blurring of vision was reported by 160 (78\%) and impaired hearing and tinnitus by 113 (55\%). Skin manifestations of nutritional deficiencies were not seen in any of the patients.

Figure 2 shows the age distribution of the 206 patients with TAN compared with the age distribution of a case series of 320 hospital and community based patients with TAN studied between 1968 and $1970 .{ }^{26}$ Forty five per cent of the 320 patients with TAN were younger than 40 years of age compared with $10 \%$ of the 206 patients in the present study. Two survivors, who remembered being part of the 1969 study, were identified in the present study. Both of them, one a 68 year old man and the other a 57 year old woman at the time of examination, reported persistence of their symptoms with periodic fluctuations.

\section{HISTORY AND NEUROLOGICAL FINDINGS IN A} SUBSET OF 66 PATIENTS WITH TAN

Five of the 66 patients with TAN, diagnosed in the two quarters selected for detailed neurological examination, who could not be evaluated for disease duration were excluded from analysis of history. The first symptom, which usually starts in the feet, was described as a 
feeling "like there is faecal soilage of the feet". The Yoruba word ralerale that describes the rather reflex act of rubbing the soles of the feet on the ground to remove the phantom soilage is locally used to describe TAN. The onset of this peculiar symptom was insidious in most of the cases. Complete remission was not reported but some cases described worsening during the rainy season. Burning of the soles or calf pain were not reported. Blurring of vision was reported by $44(72 \%)$ patients but none were completely blind. Severe cataract prevented fundoscopy in both eyes in $12(18 \%)$ patients and the contribution of cataract of various grades to the visual disturbance was difficult to quantify. Impairment of hearing or tinnitus was reported by $30(48 \%)$ patients. There was no definite sequence in the occurrence of visual and auditory symptoms with sensory symptoms on the feet. Gait abnormalities were reported by 35 patients (57\%), although only two needed walking sticks.

There was no correlation between duration of symptoms and age $(r=0.1)$ and in $82 \%$ of cases the duration of illness was less than 10 years. The proportion of patients with all the four signs was not different in those older and younger than 40 years of age. Twenty eight $(46 \%)$ of the 61 patients took local herbs as remedies for TAN and for other reasons; 15 $(26 \%)$ non-steroidal analgesics; $12(20 \%)$ haematinics; two (3\%) chloroquine; and three $(5 \%)$ mild tranquillisers regularly over the counter. Two cases $(3 \%)$ reported exposure to pesticides, which they sprayed in cocoa farms

Table 4 Neurological signs in 66 TAN patients

\begin{tabular}{|c|c|c|}
\hline Signs & $n$ & $\%$ \\
\hline Cognitive impairment & 1 & 1.5 \\
\hline Bilateral optic atrophy & 32 & 48.5 \\
\hline Facial nerve palsy & 3 & 4.5 \\
\hline Bilateral neurosensory deafness & 11 & 16.0 \\
\hline Conductive deafness & 1 & 1.5 \\
\hline \multicolumn{3}{|l|}{ Motor wasting } \\
\hline Small muscles of hands & 15 & 22.7 \\
\hline Quadriceps and calves & 6 & 9.0 \\
\hline Abnormal tone & 0 & 0.0 \\
\hline Normal muscle power & 66 & 100.0 \\
\hline \multicolumn{3}{|l|}{ Loss of deep reflexes } \\
\hline Supinator & 10 & 15.2 \\
\hline Biceps & 4 & 6.1 \\
\hline Triceps & 4 & 6.1 \\
\hline Knee & 5 & 8.0 \\
\hline Ankle & 25 & 38.0 \\
\hline \multicolumn{3}{|l|}{ Increased deep reflexes } \\
\hline Biceps & 30 & 46.0 \\
\hline Triceps & 23 & 35.0 \\
\hline Supinator & 10 & 15.2 \\
\hline Finger flexion & 2 & 3.0 \\
\hline Knee jerk & 39 & 59.1 \\
\hline Ankle jerk & 0 & 0.0 \\
\hline \multicolumn{3}{|l|}{ Superficial reflexes } \\
\hline Loss of abdominal & 60 & 91.0 \\
\hline Loss of plantar & 24 & 41.0 \\
\hline Extensor plantar & 2 & 3.0 \\
\hline Incoordination & 2 & 3.0 \\
\hline \multicolumn{3}{|l|}{ Primitive reflexes } \\
\hline Sucking & 3 & 4.5 \\
\hline Rooting & 25 & 38.0 \\
\hline Palmomental & 11 & 16.7 \\
\hline Grasp & 0 & 0.0 \\
\hline Orbicularis oris & 7 & 10.6 \\
\hline Sensory gait ataxia & 48 & 73.0 \\
\hline Positive Romberg test & 18 & 27.3 \\
\hline \multicolumn{3}{|l|}{ Sensory loss } \\
\hline Pin prick & 66 & 100.0 \\
\hline Cotton wool & 63 & 95.5 \\
\hline Joint position sense & 19 & 29.0 \\
\hline Vibration sense & 39 & 59.1 \\
\hline
\end{tabular}

over a period of about 10 years before the onset of symptoms. There was no history of alcohol misuse and only five patients smoked cigarettes. None had a history of diabetes mellitus or chronic renal disease and all urine specimens were negative for glucose and protein.

Table 4 shows the neurological findings in the 66 patients with TAN who had detailed neurological examination. Gross cognitive impairment was present in only one patient, who was 90 years old. Primitive reflexes were present in $38 \%$ without localisation to any hemisphere. The mean age in those with primitive reflexes was 69 years (SD 12), range 42-90 years compared with 62 years (SD 12), range 31- 95 years for those without primitive reflexes. Wasting of the distal muscles without fasciculations was more severe in the upper limbs. There was loss of ankle jerk in 38\% while more than half of the patients had increased biceps and knee deep reflexes. Distal symmetric impairment of pinprick sensibility was present in all patients.

\section{Discussion}

The findings of this study show the continuing occurrence of TAN in Ososa, Nigeria, described as endemic for TAN about 30 years ago. The distribution of signs in the patients follows the same trend as previously reported. ${ }^{11}{ }^{23}$ Sensory polyneuropathy is the most common sign, then sensory gait ataxia, optic atrophy, and neurosensory deafness in that order. The differences in the frequencies of signs in this study compared with published figures ${ }^{27}$ may be due to interobserver variations in the interpretation of neurological signs and not a real change in the distribution of signs of the TAN syndrome. In addition to the previously described signs, bilateral primitive reflexes were found in almost $40 \%$ of the patients suggesting the possibility of diffuse cortical lesions. The presence of primitive reflexes that was not related to age support earlier suggestions that TAN may be a neurodegenerative disease. ${ }^{11}{ }^{19}$ However, dementia has not been reported as a feature of TAN and only one patient in this study had severe impairment of cognitive function when tested with an abbreviated mini mental state examination.

Spinal cord lesions have been included in the TAN syndrome, ${ }^{23} 27$ although the extent and nature of the lesions are unclear. In this study, none of the patients had signs of transverse spinal cord lesion although exaggeration of the biceps and knee deep reflexes were found in about $50 \%$ of patients suggesting a lesion of the corticospinal tract. The presence of primitive reflexes makes localisation to the spinal cord difficult. The coexistence of degenerative lesions such as spondylosis is also possible but difficult to exclude. The neurological findings in the patients with TAN suggest that TAN affects multiple levels of the neuraxis.

The prevalence of $6.0 \%$ found in this study, although higher than the prevalence of $2.4 \%$ reported in 1969, ${ }^{11}$ may have resulted from differences in study design. Door to door screening probably increased identification of patients. In contradistinction to the previous 
study, patients were in the older age groups. This could be a reflection of a change in population structure or study design artefacts. However, age specific prevalences reported from several endemic communities, Igbile, Poka, and Iraye-Oke, in $1962,{ }^{4}$ were similar to age specific prevalence in the present study. These findings suggest that TAN affects the older age groups predominantly.

Although TAN was reported to have disappeared from the endemic communities at some period in the past 20 years this was not confirmed in Ososa. Notwithstanding that the duration of symptoms was less than 10 years in most of the patients, it cannot be concluded that there is a resurgence of cases in the absence of information about the average duration of illness, or the age specific mortality of patients compared with the general population. To butress this, only two of the patients studied in 1968 were accounted for in this study. As migration of cases out of this community is a less likely possibility, there is the possibility of higher mortality among the patients compared with the rest of the community.

It is relatively easy to distinguish TAN from other polyneuropathies and peripheral nerve diseases commonly seeing in Nigeria if the strict diagnostic criteria are used. Common causes of diseases of the peripheral nerves such as diabetes mellitus, chronic renal disease, and leprosy are easily excluded by history, clinical examination, and urinalysis. Viral syndromes such as HTLV-1, HTLV-2, and HIV, ${ }^{28}$ which also come into the differential diagnosis of spinal cord and peripheral nerve diseases, have not been shown to be prevalent in Nigeria. ${ }^{29}$ Vitamin $B_{12}$ deficiency was not demonstrated in patients with TAN in previous studies in Nigeria, ${ }^{30}{ }^{31}$ and the prominence of peripheral signs and the absence of motor signs and mental changes distinguishes TAN from vitamin $\mathrm{B}_{12}$ myelopathy. However, TAN shares some features such as optic atrophy and sensory polyneuropathy with alcohol-tobacco amblyopia. Alcohol misuse was not reported by the patients with TAN in this study. This is not surprising because in Nigeria the Ijebu ethnic group is not noted for heavy alcohol intake. More importantly, alcohol-tobacco amblyopia is now thought to be due to a nutritional cause and not due to the toxic effect of tobacco and alcohol. ${ }^{32}$

Cases of TAN cluster almost exclusively in the Ijebu speaking communities in south western Nigeria and only one of three large community based neurological surveys in Nigeria reported the occurrence of TAN outside the endemic communities at a prevalence of $3 / 1000,,^{33-35}$ but the number of cases involved is small. Although exposure to cyanide has been demonstrated in the affected communities, other possibilities such as genetic predisposition should be considered in the causation.

The current usage of tropical ataxic neuropathy gives the impression that all the syndromes so called are one disease entity. The suggestion that TAN should replace Strachan's syndrome ${ }^{1}$ further complicates the confusion in nosology, as the clinical features of the syndrome described by Strachan in 1897 are different from the clinical features of TAN in Nigeria. Numbness, cramps in the hands and feet, and dimness of sight described in Strachan's patients are similar to the symptoms of TAN but severe burning pains in the palms of the hands and soles of the feet that were worse at night and prevented sleep have not been described in TAN in Nigeria. Strachan also described warmness and hyperaemia of the palms; branny desquamation of the edges of the eyelids and margins of the lips and nostrils; wasting and clawing of the hands and feet; monoplegias; and facial nerve palsies; features not seen in TAN. Furthermore, he wrote, "I have not seen optic atrophy result from this form of neuritis". Sensory gait ataxia, well documented in TAN, were not found in Strachan's patients, as he wrote that the "typical ataxia was seen only when the muscles of the lower limbs were much wasted that the patient cannot stand upright alone . ..." For prognosis, he wrote " . . .recovery is the rule." Thus, Strachan's syndrome seems different from TAN, but it has been suggested that it might be due to arsenic poisoning. ${ }^{5}$

Various neurological syndromes described in prisoners of war $^{2}$ have also been grouped as TAN. ${ }^{5}$ The clinical features of these syndromes include leg oedema, painful feet, scrotitis, stomatitis, diarrhoea, hypertension, optic atrophy, sensory ataxia, deafness, vertigo, and exaggerated reflexes. ${ }^{36}$ The inmates in some camps responded to vitamin supplements and improvement in $\operatorname{diet}^{2}$ whereas no response was recorded in other camps. ${ }^{3}$ One follow up study of prisoners of war showed persistence of optic atrophy in $4 \%$ and symptomatic but not objective polyneuropathy in $3 \%$ of patients. ${ }^{37}$ It seems that various syndromes were seen in the camps and a single entity may not describe all of them. Some of the cases described in the prisoner of war camps with clinical features such as sore tongue, angular stomatitis, skin and scrotal scaliness, and optic atrophy resemble the syndrome described in adolescent pupils in some boarding schools in Nigeria in the 1930s. This syndrome also had acute or subacute onset and responded rapidly to dietary change and vitamin supplements. However, some of the patients with ataxia and optic atrophy seen in the prisoner of war camps resembled the TAN syndrome.

The epidemic of optic nerve neuropathy and polyneuropathy that occurred in Cuba between 1991 and $1993^{38}$ had several features in common with both tobacco-alcohol amblyopia and TAN. The optic form and the peripheral form of the epidemic were considered distinct ${ }^{39}$ with different risk factors. ${ }^{21}{ }^{38}$ The aetiology of the syndrome was not conclusively determined although reports suggest that the epidemic subsided after vitamin supplementation for the whole population. ${ }^{38}$ The rapid response of the patients to vitamin supplementation is also unlike the findings for TAN.

Konzo, the recently redescribed neurological syndrome first described in the $1930 \mathrm{~s},{ }^{40-42}$ is 
also classified as a myeloneuropathy. ${ }^{5}$ The clinical features of konzo include paraplegia; tetraparesis in a few cases; spastic dysathria; and cranial nerve deficits. ${ }^{43}{ }^{44}$ Although TAN and konzo have been attributed to dietary cyanide from heavy consumption of foods processed from the starch roots of bitter cassava, their clinical features and natural history are different.

Other neurological syndromes with some features similar to TAN include the West Indian amblyopia and the epidemic optic and peripheral neuropathy in Tanzania. ${ }^{45}$ The West Indian amblyopia, unlike TAN, affects the optic nerve predominantly although it has been associated with various neurological deficits. It has been suggested that it might be linked with Devic's syndrome. The epidemic of optic neuropathy in Tanzania described in adolescents and young adults, although associated with peripheral nerve deficits, seems also to predominantly affect the optic nerves. The aetiology is yet to be determined but no evidence of cyanide exposure has been documented.

In conclusion, TAN remains endemic in Ososa, Nigeria, and it seems distinct from Strachan's syndrome, epidemic neuropathy in Cuba, and konzo. However, it shares features with a subset of cases described from prisoner of war camps. TAN deserves both public health and scientific attention because of the possibility that it may be preventable by dietary modification, and also because understanding of its causation may further unravel the mechanism of neurodamage after exposure to dietary toxins.

We thank the members of the Ososa community, their chiefs and the monarch for their cooperation that facilitated this survey. We the monarch for their cooperation that facilitated this survey. We clinic for their support. We express our gratitude to the clinic for their support. We express our gratitude to the International Science Programme of the University of Uppsala
for providing the grant for this study. Grant support for this for providing the grant for this study. Grant support for this
work was from the International Science Program, Uppsala work was from the
University, Sweden.

Strachan H. On a form of multiple neuritis prevalent in the West Indies. Practitioner 1897;59:477-84.

2 Cruickshank E. Painful feet in prisoners of war in the far east. Lancet 1946;ii:369-72.

3 Smith D. Nutritional neuropathies in the civilian internment camp, Hong Kong, January 1942-August 1945. Brain 1946;69:209-22.

4 Money G. Endemic neuropathies in the Epe district of southern Nigeria. West Afr Med f 1958;7:58-62.

5 Roman GC, Spencer PS, Schoenberg BS. Tropical myeloneuropathies: the hidden endemias. Neurology 1985 35:1158-70.

6 Moore D. Partial loss of central acuity of vision for reading and distance in school children and its possible association with food deficiency. West Afr Med f 1930;3:46-51.

7 Moore D. Nutritional retrobulbar neuritis followed by partial optic atrophy. Lancet 1937:1225-7.

partial optic atrophy. Lancet 1937:1225-7.
8 Moore D. Pellagra or pellagra-like conditions in association Moore D. Pellagra or pellagra-like conditions in association
with deficiency of vitamin A. F Trop Med Hyg 1940;42:190with

9 Moore D. Retrobulbar neuritis with pellagra in Nigeria. $f$ Trop Med Hyg 1939;42:109-14.

10 Money GL. Clinical aspects of tropical ataxic neuropathies related to malnutrition. West Afr Med F 1959;8:3-17.

11 Osuntokun B, Monekosso G, Wilson J. Relationship of a degenerative tropical neuropathy to diet: report of a field survey. $B M 7$ 1969;i:547-50.

12 Osuntokun BO. Epidemiology of tropical nutritional neuropathy in Nigerians. Trans R Soc Trop Med Hyg 1971; 65:454-79.

13 Osuntokun BO. An ataxic neuropathy in Nigeria. A clinical, biochemical and electrophysiological study. Brain 1968;91: 215-48.

14 Monekosso G. Clinical epidemiologic observations on an ataxic syndrome in western Nigeria. Trop Geogr Med 1964; $4: 316-23$.
15 Osuntokun BO. Cassava diet, chronic cyanide intoxication and neuropathy in the Nigerian Africans. World Rev Nutr and neuropathy in the
Diet 1981;36:141-73.

16 Allem A. The origin of Mannihot esculenta Crantz (Euphorbiaceae). Genetic Resources and Crop Evolution 1994;41:133-50

17 Osuntokun BO, Langman MJ, Wilson J, et al. Controlled trial of hydroxocobalamin and riboflavine in Nigerian ataxic neuropathy. $\mathcal{F}$ Neurol Neurosurg Psychiatry 1970;33: $663-6$.

18 Osuntokun B, Langman M, Wilson J, et al. Controlled trial of combinations of hydroxocobalamin-cysteine and riboflavine-cysteine, in Nigerian ataxic neuropathy. $7 \mathrm{Neu}$ rol Neurosurg Psychiatry 1974;37:102-04.

19 Osuntokun B. Chronic cyanide intoxication of dietary origin and a degenerative neuropathy in Nigerians. Acta Horticuland a degenerative neuropa
turae 1994;375:271-83.

20 Onabolu A, Bokanga M, Rosling H. Cassava processing in a Nigerian community affected by a neuropathy attributed to dietary cyanide exposure. Tropical Science 1999;39:129-35.

21 Roman GC. Epidemic neuropathy in Cuba: a public health problem related to the Cuban Democracy Act of the United States. Neuroepidemiology 1998;17:111-5.

22 Tylleskar T, Howlett WP, Rwiza HT, et al. Konzo: a distinct disease entity with selective upper motor neuron damage. $\mathcal{F}$ Neurol Neurosurg Psychiatry 1993;56:638-43.

23 Osuntokun B. An ataxic neuropathy in Nigeria: a clinical, biochemical and electrophysiological study. Brain 1968;91: 215-48

24 Walton J. Brain's diseases of the nervous system. Oxford: Oxford University Press, 1993.

25 Bickerstaff E, Spillane J. Neurologic examination in clinical practice. London: Blackwell, 1989.

26 Osuntokun B. Epidemiology of tropical nutritional neuropathy in Nigerians. Trans $R$ Soc Trop Med 1971;65:45479.

27 Osuntokun B. Neurological disorders in Nigeria. In: Spillane J, ed. Tropical neurology. London: Oxford University Press, 1973:161-90.

28 Zehender G, Meroni L, Varchetta S, et al. Human T-lymphotropic virus type 2 (HTLV-2) provirus in circulating cells of the monocyte/macrophage lineage in patients dually infected with human immunodeficient virus type 1 and HTLV-2 and having predominant sensory polyneuropathy. $\mathcal{F}$ Virol 1998;72:7664-8.

29 Olaleye OD, Ogunniyi A, Sheng ZJ, et al. Detection of HTLV-I antibodies and DNA in blood sample of a patient with myelopathy in Nigeria. Rev Inst Med Trop 1998;40:55-7.

30 Monekosso GL, Wilson J. Plasma thiocyanate and vitamin B12 in Nigerian patients with degenerative neurological disease. Lancet 1966;i:1062-4.

31 Osuntokun BO, Langman MJ, Wilson J, et al. Controlled trial of combinations of hydroxocobalamin-cystine and riboflavine-cystine, in Nigerian ataxic neuropathy. $7 \mathrm{Neurol}$ Neurosurg Psychiatry 1974;37:102-4.

32 Adams R, Victor M, Ropper A. Principles of neurology: New York: McGraw Hill, 1997:1618.

33 Osuntokun B, Schoenberg B, Nottidge V, et al. Research protocol for measuring the prevalence of neurologic disorders in developing countries: a pilot study in Nigeria. Neuroepidemilogy 1982;1:143-53.

34 Osuntokun BO, Adeuja AO, Schoenberg BS, et al. Neurological disorders in Nigerian Africans: a communitybased study. Acta Neurol Scand 1987;75:13-21.

35 Hendrie HC, Osuntokun BO, Hall KS, et al. Prevalence of Alzheimer's disease and dementia in two communities: Nigerian Africans and African Americans. Am $\mathcal{F}$ Psychiatry 1995;152:1485-92.

36 Denny-Brown D. Neurological conditions resulting from prolonged and severe dietary restriction. Medicine 1947;26: 41-113.

37 Le Quesne PM. Persisting nutritional neuropathy in former war prisoners. BMF 1983;286:917-8.

38 The Cuba Neuropathy Field Investigation Team. Epidemic optic neuropathy in Cuba-clinical characterization and risk factors. $N$ Engl f Med 1995;333:1176-82.

39 Mojon DS, Kaufmann P, Odel JG, et al. Clinical course of a cohort in the Cuban epidemic optic and peripheral neuropathy. Neurology 1997;48:19-22.

40 Cliff J, Martelli A, Molin A, et al. Mantakassa: an epidemic of spastic paraparesis associated with chronic cyanide intoxication in a cassava staple area of Mozambique. 1, Epidemiology and clinical and laboratory findings in patients. Bull WHO 1984;62:477-84.

41 Catients. Bull WHO 1984;62:477-84. epidemic of spastic paraparesis associated with chronic cyanide intoxication in a cassava staple area of Mozambique. 2, Epidemiology and clinical and laboratory findings in patients. Bull WHO 1984;62:485-92.

42 Tylleskar T, Banea M, Bikangi N, et al. Epidemiological evidence from Zaire for a dietary aetiology of konzo, an upper motor neuron disease. Bull WHO 1991;69:581-9.

43 Howlett WP, Brubaker GR, Mlingi N, et al. Konzo, an epidemic upper motor neuron disease studied in Tanzania. Brain 1990;113:223-35.

44 Howlett W. Konzo: A new human disease entity. Acta Horticulturae 1994;375:323-9.

45 Roman G. Tropical myeloneuropathies revisited. Curr Opin Neurol 1998;11:539-44.

46 Plant G, Mtanda A, Arden G, et al. An epidemic optic neuropathy in Tanzania: characterisation of the visual disorder and associated peripheral neuropathy. $f$ Neurol Sci 1997;145:127-40. 